\title{
QUANTO VALE A PRODUÇÃO PARA O AUTOCONSUMO NO MEIO RURAL? UM ESTUDO DE CASO NO MUNICÍPIO DE CORONEL FREITAS NO OESTE CATARINENSE
}

\author{
Cristiane Tonezer ${ }^{1}$ \\ Elisângela Pinheiro ${ }^{2}$ \\ Loriane Pagnussat ${ }^{3}$
}

\begin{abstract}
RESUMO
Este trabalho tem como objetivo analisar a produção para o autoconsumo na Comunidade de Roncador, localizada no município de Coronel Freitas (SC). Trata-se de uma pesquisa qualitativa com caráter exploratório e descritivo. Para a aquisição dos dados, foi realizada uma entrevista semiestruturada. A seleção foi aleatória e a amostra foi por saturação (método bola de neve), ou seja, no momento em que as informações começaram a se repetirem a coleta foi finalizada. A análise foi de conteúdo temático. Como resultado, observou-se que todos os entrevistados produzem para o autoconsumo, tendo uma grande diversidade de alimentos produzidos na horta, pomar, produção de origem animal, grãos e produtos beneficiados. Observou-se, também, que os entrevistados atribuem múltiplas funções à produção para o autoconsumo, dentre estas, destacam-se o acesso a um alimento mais saudável, a economia, quando observam que não há necessidade de comprar o que produzem, a preservação dos costumes, a possibilidade de continuarem ativos produzindo seus alimentos e a integração social, possível através da reciprocidade que se dá na troca destes produtos entre vizinhos e amigos.
\end{abstract}

Palavras-chave: autoconsumo, integração social, alimentos saudáveis, meio rural, produção familiar.

\section{HOW MUCH IS THE PROCESS FOR SELF-CONSULTING IN THE COUNTRYSIDE? A CASE STUDY IN CITY OF CORONEL FREITAS IN THE WEST CATARINENSE}

\begin{abstract}
This paper aims to analyze the production for self-consumption in the Roncador Community, located in Coronel Freitas (SC). It is a qualitative research with exploratory and descriptive character. For data acquisition, a semi-structured interview was performed. The selection was random and the sample was by saturation (snowball method), that is, when the information began to repeat the collection was completed.
\end{abstract}

1 Graduação em Desenvolvimento Rural e Gestão Agroindustrial (UERGS). Mestrado em Desenvolvimento Rural (UFRGS). Doutorado em Desenvolvimento Rural (UFRGS). Docente do Programa de Pós-Graduação em Políticas Socais e Dinâmicas Regionais (Unochapecó). E-mail: tonezer@unochapecó.edu.br

${ }^{2}$ Graduação em Engenharia de Produção (SETREM). Mestre em Engenharia de Produção (UFSM). Docente das áreas de Ciências Exatas e Ambientais (Unochapecó).E-mail: e.pinheiro@unochapeco.edu.br.

3 Bacharel em Ciências Econômicas (Unochapecó). E-mail: lori26@unochapeco.edu.br. 
The analysis was thematic content. As a result, it was observed that all respondents produce for self-consumption, having a great diversity of food produced in the garden, orchard, animal production, grain and processed products. It was also observed that the interviewees assign multiple functions to the production for self-consumption, among them the access to a healthier food, the economy, when they observe that there is no need to buy what they produce, the preservation of food customs, the possibility of remaining active in producing their food and social integration, made possible through the reciprocity that occurs in the exchange of these products between neighbors and friends.

Keywords: self-consumption, social integration, healthy food, countryside, family production.

\section{INTRODUÇÃO}

De acordo com Grisa (2007, p. 15), tem-se observado que nas últimas décadas o meio rural vem passando por transformações nas atividades técnicoprodutivas, aflorando um antagonismo entre estas transformações e a manutenção das formas tradicionais de organização, produção e cultivo de alimentos. Em que, a enxada, as sementes crioulas e a produção dos próprios fertilizantes (adubos) foram sendo substituídas por maquinário modernos, sementes geneticamente modificadas vindas do mercado e fertilizantes e agrotóxicos. Heisler, Renk e Bonamigo (2018) e Mior (2007) reforçam as mudanças que vêm ocorrendo no meio rural principalmente no oeste catarinense que é uma região caracterizada pela existência dos complexos agroindústrias, destacando-se a produção e o processamento da carne suína e de aves.

Os complexos agroindustriais têm como característica as relações entre os setores da indústria, da agricultura, do comércio e de serviços, onde, o setor agropecuário é integrado via a indústria por meio de empresas integradoras, que realizam ações que visam modernizar e ampliar a participação de micro, de pequenas e de médias empresas em todos os âmbitos da vida econômica (FAJARDO, 2008; PIVA, 2010).

Antes da inserção das empresas integradoras, os colonos tinham praticamente toda sua produção voltada para o autoconsumo e o excedente era vendido ou trocado por insumos não produzidos em suas propriedades (PELEGRINI; GAZOLLA, 2013). Com as mudanças ocorridas no meio rural associadas com a modernização da agricultura, observa-se que existe uma diminuição da produção para o autoconsumo (MINETTO, 2011). Para Konrad e Silva (2012), o processo de integração acabou alterando o modo de vida do meio rural, gerando uma perda de autonomia que transformou o colono em um trabalhador assalariado. Ideia está reforçada por Forneck e Klug (2015) onde as empresas integradoras trouxeram consigo problemas como os impactos ambientais, dentre eles a degradação dos recursos hídricos e do solo. Outra questão relatada é sobre a produção integrada que contribuiu para a insegurança alimentar ${ }^{4}$ das famílias, pois estas ficaram à mercê de regras visando um a produção que requer a utilização de defensivos para otimizar a produção, se restringindo a produzir para o autoconsumo, passaram a produzir o que

\footnotetext{
${ }^{4}$ Segundo Maluf e Menezes (2007), a segurança alimentar estaria ancorada em três itens essenciais: a qualidade nutricional dos alimentos e a ausência de agrotóxicos que possam causar danos à saúde humana; os hábitos e a cultura alimentar característicos de cada local, de cada grupo social; e a sustentabilidade do sistema alimentar, quer dizer, a contínua produção e presença de alimentos, a insegurança alimentar segue 0 caminho contrário a estes princípios.
} 
demanda o mercado consumidor, e o que antes podiam ser produzidos de forma mais natural nas propriedades passou a ser adquirido no mercado (MENASCHE; MARQUES; ZANETTI, 2008).

Apesar das transformações ocorridas, nem todos os agricultores desta região abandonaram seus hábitos tradicionais dentre eles a produção de alimentos vinda do trabalho familiar designada ao consumo da família. Assim, segundo Grisa (2007, p. 15), a produção para o autoconsumo não é um resquício do passado ou o que sobrou da tradição, mas a tradição se fortalecendo em um novo contexto.

Gazolla (2004) destaca que a produção para o autoconsumo propicia uma alimentação com uma maior diversidade, mais nutritiva e segura. No ato de produzir e consumir o alimento, o agricultor potencializa o que se poderá obter em termos de quantidade suficiente, auxiliando para um distanciamento da restrição alimentar.

Tendo em vista que poucos são os trabalhos realizados nesta perspectiva, principalmente quando se trata de Santa Catarina e dada a crescente relevância socioeconômica e cultural desta produção, sentiu-se a necessidade de obter informações sobre o autoconsumo, se é uma prática ainda existente nas propriedades rurais e em que proporções que ela ocorre.

Neste sentido, este artigo tem como objetivo, analisar a produção para o autoconsumo na Comunidade Roncador, município de Coronel Freitas na região oeste do estado de Santa Catarina. Visando investigar como ocorre a produção para autoconsumo entre os agricultores, identificar se as atividades de produção de autoconsumo desempenhadas pelas famílias, ser informativo para a comunidade cientifica e social, sobre este modelo familiar da atividade produtiva que introduz um repertório cultural e de identidade, e por fim, mostrar a importância da produção de autoconsumo na melhoria das condições de vida, alimentação diversificada e segurança alimentar.

Este estudo está estruturado em cinco seções. A seção um apresenta uma breve introdução sobre o desenvolvimento da agricultura na região oeste de SC, bem como, os objetivos desta pesquisa. A seção dois traz uma breve revisão bibliográfica referente a produção para o autoconsumo; na seção três, é apresentada a metodologia utilizada no trabalho, bem como as informações socioeconômicas obtida com os entrevistados; a seção quatro, apresenta as discussões e os resultados obtidos com o desenvolvimento do estudo e por fim, a seção cinco apresenta as considerações finais e a conclusão do estudo.

\section{A PRODUÇÃO PARA O AUTOCONSUMO: DEFININDO CONCEITOS}

Os primeiros estudos sobre produção para o autoconsumo, segundo Félix e Coelho (2010), datam do início do século XX, em unidades de produção familiar russas, observadas por Alexander Chayanov (1974). Esse autor estudou em um contexto mais microeconômico nas unidades camponesas, buscando compreender como a família trabalhava para preencher as necessidades fundamentais dos seus membros e, em um segundo plano, para acumular capital.

Os estudos de Chayanov (1974) foram os primeiros a debater sobre o campesinato, relatando detalhadamente de que maneira era a organização econômica e social das famílias camponesas e de eu forma as unidades familiares chegaram a um equilíbrio interno, entre o trabalho e o consumo da família. Neste sistema havia uma lógica econômica, em que, cada família possuía uma dinâmica demográfica própria, que influenciava no volume de trabalho e no consumo necessário para assegurar a sobrevivência da mesma. Portanto, para se chegar ao pressuposto do bem-estar familiar, tendo alimentos necessários ao consumo, as famílias faziam 
uso de diferentes estratégias. O que e se aproxima dos processos produtivos voltados ao autoconsumo alimentar nas famílias rurais atualmente.

Ainda para este mesmo autor destaca que, mesmo que os preços dos produtos eram ditados pelo mercado, o camponês não perdia a autonomia na produção, mesmo que se dedicasse mais a uma cultura de mercado, ainda assim mantinha as culturas de subsistência.

O princípio básico de organização da unidade econômica camponesa, segundo a visão de Chayanov, reside na satisfação das suas necessidades, concebida simultaneamente como uma unidade de produção e consumo. Trabalho, terra e capital formam um conjunto indissociável de variáveis dependentes, estabelecidas num processo de equilíbrio entre o dispêndio de trabalho e as necessidades de consumo da unidade. As decisões sobre a produção e o consumo estão relacionadas a fatores internos, a chamada motivação individual. A quantidade do produto do trabalho depende do tamanho e da composição da família trabalhadora e do grau de auto exploração (este prescrito pelas necessidades internas de consumo). O equilíbrio será afetado pelo tamanho da família, membros aptos ou não ao trabalho, e pela dimensão da terra, sujeita a alterações por herança, casamentos etc., a promover a diferenciação no espaço rural, denominado pelo autor de diferenciação demográfica. (CARNEIRO, 2009, p. 55).

Van der Ploeg (2016) observa-se que as características trazidas por Chayanov no século XIX continuam presentes na atualidade.

Trazendo esta discussão para o Brasil, Grisa (2007) observa-se que os estudos focados para a produção destinadas ao autoconsumo não é tema de muitos estudos, isso ocorre, pelo fato desta prática estar destinada ao esquecimento, além de um preconceito existente, por fadarem que essa prática simboliza uma cultura que vai no ciclo contrário ao da modernização. O que contribuiu para esta visão, é a ideologia preconizada na Revolução $V^{2} r_{d e}{ }^{5}$, repercutindo este pensamento, às políticas públicas pouco tem considerado esta produção, algumas vezes até contribuindo para sua diminuição. " Portanto, observa-se que a produção para o autoconsumo é compreendida como a produção da família e que se destina ao seu próprio consumo.

O autoconsumo é colocado como um método utilizado pelas famílias visando garantir a autossuficiência sobre uma dimensão essencial: a alimentação. Por certo, a produção para autoconsumo viabiliza o acesso direto aos alimentos, seguindo direto da unidade de produção (lavoura) para a unidade de consumo (casa) (GAZOLLA; SCHNEIDER, 2007).

Muitas são as definições da produção de autoconsumo dentre elas podemos destacar que o autoconsumo abrange a produção e consumo pela família, sendo: alimentos, instrumentos domésticos, artesanato, lenha, materiais para construção ou para fabricação de objetos de uso da família, plantas medicinais, destaca-se também o autoconsumo como a parcela da produção agropecuária resultante de produtos primários beneficiados, produzida no estabelecimento familiar e destinada ao consumo da família, dos animais e outros usos da atividade produtiva (GARCIA FILHO, 1999, LEITE, 2004 e GRISA e SCHNEIDER, 2008). Woortmann e Woortmann

${ }^{5}$ Segundo Ganimi e Andrades (2007, p. 2), a Revolução Verde se caracteriza pelo uso intensivo de agrotóxicos e fertilizantes sintéticos na agricultura, é um fato presente no campo e está vigente na vida de muitos produtores em diversas áreas do mundo, visando o avanço tecnológico e o aumento da produtividade. 
(1997) complementam a afirmação ao citar que o autoconsumo tem grande relevância para estabelecer a identidade do agricultor e de sua família, promover a satisfação alimentar da família com a menor dependência externa.

Em relação ao repertório cultural define-se como um conjunto de noções estratégicas que direcionam as ações práticas e o comportamento dos agricultores. Portanto, o repertório cultural dos agricultores familiares de hoje não é o mesmo daquelas famílias onde suas produções são menos inseridas nos mercados, especialmente antes da modernização tecnológica da agricultura. No entanto, elementos como esse permanecem, como é o caso da produção de alimentos para o consumo familiar (VAN DER PLOEG, 1993).

A produção para o autoconsumo nas famílias permite uma independência produtiva e reprodutiva. Esta independência é gerada por manter interna a unidade produtiva, o principal elemento responsável pela reprodução do grupo doméstico. Dessa maneira, depende cada vez menos dos fatores externos para poder se reproduzir socialmente. Por meio do autoconsumo, as famílias conseguem ter uma autonomia no ambiente em que estão inseridas, não ficando vulnerável aos fatores externos como por exemplo o mercado (GAZOLLA; SCHNEIDER, 2007).

Gazolla (2004) destaca que a produção para o autoconsumo facilita uma alimentação diversificada e mais nutritiva. No ato de produzir e consumir o alimento, o agricultor potencializa o que se poderá obter em termos de quantidade suficiente, auxiliando para um distanciamento da restrição alimentar.

Neste estudo a produção para o autoconsumo, refere-se à produção animal, vegetal e beneficiamentos caseiros produzidos e consumidos pelas famílias.

\section{METODOLOGIA DA PESQUISA}

Para a realização deste estudo foram utilizados alguns procedimentos, abordagens e objetivos com base nos autores Gerhardt e Silveira, (2009); Markoni e Lakatos (2003); Gil (2007) e Fonseca (2002). Da qual, caracteriza-se de abordagem qualitativa, quanto aos objetivos é de caráter exploratório, analítico descritivo, quanto a natureza é uma pesquisa básica e quanto aos procedimentos é de caráter bibliográficos, de campo e de estudo de caso.

Esta pesquisa é de abordagem qualitativa pois tem como objetivo principal aprofundar-se no significado dos fenômenos a serem estudados, neste caso analisar a produção de autoconsumo na identidade cultural no território rural do Oeste de Santa Catarina. É de caráter exploratório pois visa conhecer a comunidade de Roncador quanto ao assunto proposto e posteriormente descrever as características dessa comunidade. De natureza básica, pois visa gerar novos conhecimentos para o avanço da ciência a fim de entender a cultura e meios de produção de autoconsumo dos moradores da comunidade objeto deste estudo. E bibliográfica pois foi realizado um estudo em artigos e meios digitais a fim de embasar este assunto, caracteriza-se de campo pois foi realiza coleta de dados junto as pessoas objeto deste artigo e também de caso porque foi aplicada a uma localidade específica.

Para a aquisição dos dados, aplicou-se a entrevista semiestruturada, onde foram entrevistados dez agricultores familiares a Comunidade Roncador, localizada no município de Coronel Freitas. Os critérios para a escolha dos participantes se deu de forma aleatória utilizando o método snowball (bola de neve). Neste método o primeiro sujeito sugere outro participante e assim sucessivamente. Quanto ao número de participantes, levou-se em conta que a pesquisa qualitativa é influenciada pela saturação dos dados, ou seja, quando houver certa redundância ou repetição das informações (MINAYO, 2008). Segundo Ghiglione e Matalon (1997), é inútil requisitar um grande número de pessoas quando se utiliza métodos qualitativos, pois são 
pouquíssimas as vezes que é possível o surgimento de novas informações após a vigésima ou trigésima entrevista. A fim de manter o anonimato dos sujeitos atribuiuse número de 1 a 10 para a identificação dos mesmos. Para ser entrevistado, bastava que as famílias residissem no meio rural e estivesse disposta a participar da pesquisa. As entrevistas foram agendadas previamente e realizadas na própria residência familiar, onde cada família escolheu um (a) integrante para ser entrevistado (a), cada entrevista teve uma duração média de 45 minutos.

Para a coleta dos dados, primeiro identificou-se e caracterizou-se os produtos para o autoconsumo nas propriedades dos entrevistados. Foram considerados produção para autoconsumo a produção animal, vegetal e transformação caseira produzida pela unidade familiar e consumida por ela. Para a execução dos cálculos de produtos sazonais, como o pomar e horta, foram realizadas médias de consumo mensal. Com a quantidade anual informada, esta foi dividida pelos meses do ano a fim de obter o número que demonstrasse a situação mais próxima da produção mensal real. Para atribuir um valor à esta produção, primeiramente, o entrevistado foi questionado quanto ele achava que estes produtos valiam em termos financeiros. Após foram feitos cálculos dos mesmos produtos atribuindo a estes o valor ofertado pelo supermercado ${ }^{6}$. E por fim, a partir de uma análise de conteúdo temático, descreveu-se sobre a percepção que os agricultores familiares tinham em relação à esta produção.

\section{O UNIVERSO DE ANÁLISE DO ESTUDO}

A região oeste catarinense foi colonizada, em sua maior parte, por gaúchos de origem alemã e italiana. Também foi onde surgiram algumas das maiores empresas do setor agroindustrial, especialista na produção de carne suína e de frango. Nesta região está localizado o município de Chapecó, considerada a capital do oeste e polo agroindustrial, sendo a sexta cidade mais populosa do estado, com 198.190 habitantes (KAISER, 2014).

A Comunidade Roncador, área de estudo desta pesquisa, é formada por sessenta famílias, localizada a $19 \mathrm{~km}$ do município de Coronel Freitas na área rural (CORONEL FREITAS, 2013).

De acordo com o Instituto Brasileiro de Geografia e Estatística (IBGE, 2010), Coronel Freitas apresentava uma população de 10.213 habitantes, 6.067 estão localizados no meio urbano e 4.146 estão localizados no meio rural. O município iniciou sua colonização em 1929, com famílias agricultoras de origem italiana, oriundas do Rio Grande do Sul, que foram se estabelecendo, buscando melhores condições de vida (CORONEL FREITAS, 2012). A economia inicial do município era de subsistência, com pequenos cultivos de milho e feijão, essa se modificando nas décadas de 1960 e 1970. A contribuição das terras férteis tornou o município um verdadeiro celeiro de grãos. A partir de 1980, revelou-se forte na produção de suínos, despontando novas formas econômicas, como a agropecuária e a agricultura, destacando que os produtores plantavam grãos para o seu próprio consumo. A partir do surgimento das agroindústrias no município, aliado ao sistema de integração, esses fatores serviram para impulsionar o desenvolvimento da suinocultura, além de viabilizar a produção de aves.

\footnotetext{
${ }^{6} \mathrm{O}$ valor de cada produto foi calculado fazendo-se uma média de três supermercados da região. Para se obter os valores de cada um, em produtos que tinham mais de uma marca, foi coletado o valor mais caro e mais barato, e feito uma média, posteriormente a média entre os três mercados. Um dos casos que pode ser citado é o da carne bovina, que foi coletado o valor da carne de primeira e a carne de segunda, feito uma média desses dois valores e, em seguida, a média entre os três mercados.
} 
Através da análise inicial das informações obtidas com a pesquisa observa-se que, em relação a faixa etária dos entrevistados, dois possuíam de 60 a 79 anos, cinco de 50 a 59 anos e três tinham dentre 30 e 49 anos. Em relação a escolaridade, sete não chegaram a concluir o Ensino Fundamental, dois tinham Ensino Fundamental completo e um dos entrevistados tinha Ensino Superior completo.

De acordo com Lima (2010), os pais de antigamente levavam consigo os filhos ao trabalho, para poderem aprender uma atividade desde crianças, o estudo vinha depois, pois eles achavam que os filhos deveriam crescer logo para ir à luta, pois consideravam que a vida era dura e cheia de dificuldades.

Todos os entrevistados residiam com seus cônjuges todos tinham filhos e seis deles os filhos estavam residindo na propriedade. Dois dos entrevistados, além residia na propriedade com o sogro e a sogra.

Como principal atividade da renda agrícola das propriedades entrevistadas, destacam-se a bovinocultura de leite e a avicultura, sendo que três famílias desenvolvem ambas as atividades, três trabalham apenas com bovinocultura de leite e quatro citaram não possuir renda agrícola. Dos quatro entrevistados que não possuem renda agrícola na família, dois são aposentados e dois servidores públicos municipais.

Ceccatto (2014) destaca que, no município de Coronel Freitas, a produção de leite é a mais importante economia agrícola da maioria das famílias.

A bovinocultura de leite, de certa forma, assume o papel de grande substituto compensatório para os pequenos produtores que não conseguiram acompanhar as exigências de mercado impostas pela produção da suinocultura e/ou avicultura. A produção leiteira é uma atividade com caráter de trabalho familiar (JOCHIMS; DORIGON; PORTES, 2016).

Em relação à produção de alimentos para o autoconsumo, todos os entrevistados possuem horta em suas propriedades, $100 \%$ deles ressaltam que o que é produzido é suficiente para atender as necessidades da família, inclusive, para dar aos filhos que não moram na propriedade.

Os principais cultivos da horta citados foram: alface, beterraba, cenoura, cebola, salsa, repolho, tomate, batata-doce, alho, radiche, couve-flor, pimentão, brócolis, mandioca, couve, moranga; outros também foram citados em menor número, como acelga, chuchu e pepino. Os cultivos de hortaliças mencionados com mais frequência pelos entrevistados foram alface, beterraba, salsa, repolho, batata-doce, alho, radiche, mandioca e moranga, o que constata-se uma diversidade grande de hortaliças nestas propriedades.

Nove dos entrevistados tem pomar, as principais frutíferas cultivadas são laranja, bergamota e limão a produção atende às necessidades da família, "tem vezes que dá tanto de uma fruta que a gente dá até pros animais comer" (Entrevistado 4).

Em relação ao entrevistado que citou não ter pomar, esta destaca que vai construí-lo brevemente, porém, como ela está recentemente morando na propriedade, ainda não teve tempo para organizá-lo.

Outra produção para o autoconsumo analisada foi a de grãos, em que todas as propriedades produzem e afirmam que o que é produzido atende à necessidade familiar, destas nove produzem feijão, oito produzem milho e quatro delas produzem pipoca.

Todos os entrevistados citaram produzir pelo menos um produto de origem animal dentre os quatro tipos de carne relacionadas, que são, bovina, suína, frango e peixe. Sendo que nove deles produzem além da bovina uma das quatro mencionadas e dois deles produzem apenas carne bovina.

Quando analisada só a produção de aves, sete deles produzem carne de frango, destes, dois deles exercem a atividade de avicultura. Para estes dois, as aves para consumo são separadas das demais, o que, segundo eles, garante à família uma 
alimentação mais natural. Estes animais separados são tratados à base de milho por um tempo maior do exigido pelo mercado consumidor, o que, para os entrevistados, possibilita uma "limpeza" do frango, além da carne ficar mais saborosa.

Segundo Carvalho e Souza (2012), a criação de frangos já existe há muito tempo nas pequenas e médias propriedades, estes viviam soltos, ciscando o dia todo, onde a produção era em menor escala apenas para o consumo próprio de carne e ovos, que era alimentada com o milho produzido na propriedade.

Segundo informações do Guia alimentar para a população brasileira (BRASIL, 2014), a alimentação deve ser variada, composta de todos os grupos alimentares como grãos, raízes, tubérculos, farinhas, legumes, verduras, frutas, castanhas, leite, ovos e carnes, e dentro destes grupos ter uma variedade também de cada tipo, como feijão, arroz, milho, batata, mandioca, tomate, abóbora, laranja, banana, frango, peixe, pois cada alimento tem uma quantidade específica de nutrientes que, em conjunto, suprem as necessidades nutricionais diárias.

Em relação à transformação caseira de produtos, por parte dos entrevistados, oito deles tem algum tipo de alimento que é beneficiado na propriedade e dois não beneficiam nenhum tipo de alimento. Dentre os alimentos oriundos da transformação caseira estão a banha, o salame, as chimias, o vinho, o queijo, as conservas, compotas e o açúcar mascavo.

Nos itens mais produzidos (banha, salame, chimia e vinho), fica clara a influência da cultura nos hábitos alimentares. De acordo com Grisa e Schneider (2008, p. 13), salame e vinho são tipicamente italianos, o que reafirma as raízes dos primeiros colonizadores instalados no município.

Trazendo o conceito de segurança alimentar para complementar estas reflexões, destaca-se, segundo o Conselho Nacional de Segurança Alimentar e Nutricional (CONSEA, 2004).

Segurança alimentar e nutricional é a realização do direito de todos ao acesso regular e permanente a alimentos de qualidade, em quantidade suficiente, sem comprometer o acesso a outras necessidades essenciais, tendo como base práticas alimentares promotoras de saúde, que respeitem a diversidade cultural e que sejam sociais, econômicas e ambientalmente sustentáveis (CONSEA, 2004, p. 4).

Uma das características que associa a produção para autoconsumo aos princípios da segurança alimentar é o respeito às preferências alimentares e práticas de preparo, armazenamento e consumo. Segundo o IPEA (2013, p. 14): "Neste sentido, é possível afirmar que o autoconsumo tem uma função de preservação da cultura, dado que muitas destas práticas são repassadas de pais para filhos, em sinergia com as condições socioambientais e a própria história local. "

Complementando a relação entre os princípios da segurança alimentar e a produção para o autoconsumo, segundo os entrevistados, além de "não precisar comprar no mercado", economizando recursos financeiros, a produção para o autoconsumo permite que a família tenha uma alimentação mais saudável. Segundo (BRASIL, 2014) para uma refeição ser nutricionalmente balanceada, saborosa, culturalmente apropriada e promotora de sistemas alimentares social e ambientalmente sustentáveis, a alimentação deve estar ancorada em uma variedade de alimentos in natura ou s seja pouco processada, características estas que se mostraram presentes nos produtos produzidos pelos entrevistados neste estudo. 


\subsection{PRODUÇÃO PARA O AUTOCONSUMO: VALOR ATRIBUÍDO PELOS ENTREVISTADOS E O VALOR DE MERCADO}

O objetivo deste tópico é trazer informações referentes à quanto vale a produção para o autoconsumo (em termos monetários) comparando está com o valor que é vendido nos mercados da região.

Para uma melhor compreensão das informações obtidas, optou-se por dividir a análise em seis blocos. Primeiro, aborda sobre a horta; em um segundo momento, sobre o pomar; após, acerca da produção animal; em seguida, sobre a produção de grãos; na sequência, discorre-se sobre produtos beneficiados; e, por fim, foi apresentada uma tabela com a soma de toda esta produção.

\subsubsection{Horta}

Em relação aos produtos da horta, observa-se na tabela 1 que todos os entrevistados citaram um valor mensal inferior do que vale esta produção se comparada com o valor de mercado. Observa-se que na média o valor fica $74,10 \%$ maior do produto adquirido no mercado. A maior diferença pode ser observada no Entrevistado 7 que gastaria $88,65 \%$ a menos com a aquisição de produtos para a alimentação.

Tabela 1 - Valor mensal de produtos da horta para o autoconsumo atribuído pelos entrevistados e valor de mercado.

\begin{tabular}{lccc}
\hline Entrevistados & $\begin{array}{c}\text { Valor atribuído pelos } \\
\text { entrevistados (R\$) }\end{array}$ & $\begin{array}{c}\text { Valor de mercado } \\
\text { (R\$) }\end{array}$ & $\%$ \\
\hline Entrevistado 1 & 250,00 & 656,36 & 61,91 \\
Entrevistado 2 & 100,00 & 468,48 & 78,65 \\
Entrevistado 3 & 100,00 & 456,84 & 78,11 \\
Entrevistado 4 & 150,00 & 451,60 & 66,78 \\
Entrevistado 5 & 100,00 & 465,62 & 78,52 \\
Entrevistado 6 & 100,00 & 454,52 & 78,00 \\
Entrevistado 7 & 50,00 & 440,40 & 88,65 \\
Entrevistado 8 & 250,00 & 521,99 & 52,11 \\
Entrevistado 9 & 100,00 & 452,08 & 77,88 \\
Entrevistado 10 & 100,00 & 508,98 & 80,35 \\
\hline
\end{tabular}

Fonte: Elaborada pelos autores (2017).

Um dos fatores que contribui para que os entrevistados tenham esta percepção de valores muito abaixo do que é comercializado no mercado pode estar relacionado ao fato de que, ao valorar os produtos que são voltados à comercialização (neste caso, o leite e as aves), os valores pagos pelos intermediários geralmente são bem abaixo do preço que são vendidos no mercado, o que provavelmente leva os entrevistados a realizarem este tipo de associações.

Outro fator que pode contribuir para esta desvalorização é o fato de que os entrevistados não fizeram um cálculo preciso desta produção, muitas vezes deixando de fora itens importantes, como a mão de obra.

\subsubsection{Pomares}

$\mathrm{Na}$ análise dos produtos do pomar, onde nove entrevistados possuem o mesmo, seis atribuíram menor valor a esta produção se comparada com o valor de mercado, conforme mostra a tabela 2. 
Tabela 2 - Valor mensal dos produtos do pomar para o autoconsumo atribuído pelos entrevistados e valor de mercado

\begin{tabular}{ccc}
\hline Entrevistados & $\begin{array}{c}\text { Valor atribuído pelos entrevistados } \\
\mathbf{( R \$ )}\end{array}$ & $\begin{array}{c}\text { Valor de mercado } \\
\mathbf{( R \mathbf { S } )}\end{array}$ \\
Entrevistado 1 & 300,00 & 397,32 \\
Entrevistado 2 & 100,00 & 84,78 \\
Entrevistado 3 & 30,00 & 36,80 \\
Entrevistado 4 & 300,00 & 313,42 \\
Entrevistado 5 & 200,00 & 854,41 \\
Entrevistado 6 & 200,00 & 53,59 \\
Entrevistado 7 & 100,00 & 142,56 \\
Entrevistado 8 & 200,00 & 186,42 \\
Entrevistado 9 & 150,00 & 392,43 \\
Entrevistado 10 & 0,00 & 0,00 \\
\hline Fonte: Elaborada pelos autores (2017).
\end{tabular}

Ainda referente à tabela 2, três entrevistados citaram um valor maior para os produtos do pomar do que o valor de mercado.

\subsubsection{Grãos}

Sobre a produção de grãos para o autoconsumo, apenas quatro dentre os dez entrevistados atribuíram maior valor a esta produção se comparada com o valor de mercado. Vide tabela 3.

Tabela 3 - Valor mensal da produção de grãos para o autoconsumo atribuído pelos entrevistados e valor de mercado.

\begin{tabular}{ccc} 
Entrevistados & $\begin{array}{c}\text { Valor atribuído pelos entrevistados } \\
\text { (R\$) }\end{array}$ & $\begin{array}{c}\text { Valor de mercado } \\
\text { (R\$) }\end{array}$ \\
Entrevistado 1 & $\mathbf{1 5 0 , 0 0}$ & $\mathbf{2 5 4 , 1 0}$ \\
Entrevistado 2 & 50,00 & 24,92 \\
Entrevistado 3 & 20,00 & 8,54 \\
Entrevistado 4 & $\mathbf{5 0 , 0 0}$ & $\mathbf{8 6 , 6 1}$ \\
Entrevistado 5 & 70,00 & 18,49 \\
Entrevistado 6 & $\mathbf{1 0 , 0 0}$ & $\mathbf{4 9 , 7 5}$ \\
Entrevistado 7 & 50,00 & 8,54 \\
Entrevistado 8 & 100,00 & 12,81 \\
Entrevistado 9 & 50,00 & 24,72 \\
Entrevistado 10 & $\mathbf{3 0 , 0 0}$ & $\mathbf{6 1 , 1 5}$ \\
\hline
\end{tabular}

Fonte: Elaborada pelos autores (2017).

Já para a maioria dos entrevistados (seis), o preço que eles atribuíram aos grãos para o autoconsumo foi maior do que o encontrado no mercado. Esta característica pode estar associada à questão de que eles tenham maior acesso à informação sobre o preço da produção de grãos, que, inclusive, muitas vezes é anunciada nos meios de comunicação. 


\subsubsection{Produção animal e produtos beneficiados}

Em relação aos produtos de origem animal observou-se que todos os entrevistados atribuíram um menor valor do que é produzido na propriedade se comparados com o valor de mercado, sendo que para dois dos entrevistados o valor quase triplicou (entrevistado 1 e entrevistado 8). Todos os valores referentes aos produtos de origem animal podem ser visualizados na tabela 4.

Tabela 4 - Valor mensal dos produtos de origem animal para o autoconsumo atribuído pelos entrevistados e valor de mercado

\begin{tabular}{ccc} 
Entrevistados & Valor atribuído pelos entrevistados (R\$) & $\begin{array}{c}\text { Valor de mercado } \\
\mathbf{( R \$ )}\end{array}$ \\
Entrevistado 1 & 400,00 & $1.124,94$ \\
Entrevistado 2 & 450,00 & 592,35 \\
Entrevistado 3 & 450,00 & 626,1 \\
Entrevistado 4 & 380,00 & 892,45 \\
Entrevistado 5 & 300,00 & 890,21 \\
Entrevistado 6 & 300,00 & 468,09 \\
Entrevistado 7 & 150,00 & 292,05 \\
Entrevistado 8 & 530,00 & $1.371,60$ \\
Entrevistado 9 & 500,00 & 852,1 \\
Entrevistado 10 & 20,00 & 28,16 \\
\hline
\end{tabular}

Fonte: Elaborada pelos autores (2017).

Oito dos dez entrevistados beneficiavam produtos em suas propriedades para o autoconsumo conforme mostra a tabela 5 .

Tabela 5 - Valor mensal atribuído pelos entrevistados e valor de mercado dos produtos para o autoconsumo beneficiados na propriedade

\begin{tabular}{lcc} 
Entrevistados & $\begin{array}{c}\text { Valor atribuído pelos entrevistados } \\
\text { (R\$) }\end{array}$ & $\begin{array}{c}\text { Valor de mercado } \\
\text { (R\$) }\end{array}$ \\
Entrevistado 1 & 150,00 & 221,47 \\
Entrevistado 2 & 350,00 & 476,88 \\
Entrevistado 3 & 0,00 & 0,00 \\
Entrevistado 4 & 352,00 & 750,65 \\
Entrevistado 5 & 250,00 & 414,93 \\
Entrevistado 6 & 100,00 & 203,73 \\
Entrevistado 7 & 0,00 & 0,00 \\
Entrevistado 8 & 260,00 & 468,57 \\
Entrevistado 9 & 50,00 & 253,69 \\
Entrevistado 10 & 105,00 & 139,15 \\
\hline
\end{tabular}

Fonte: Elaborada pelos autores (2017).

Por fim, o somatório de toda a produção mensal para o autoconsumo, possível de ser observado na tabela 6 , conclui que todos os entrevistados atribuíram menor valor aos seus produtos se comparados com o valor de mercado.

Em percentuais os valores dos produtos quando adquiridos no mercado em média são 52,45 \% maiores em relação quando produzidos na propriedade. 
Tabela 6 - Valor de todos os produtos citados pelos entrevistados da pesquisa e valor de mercado

$\begin{array}{ccc}\text { Entrevistados } & \text { Valor total entrevistado (R\$) } & \text { Valor total mercado (R\$) } \\ \text { Entrevistado 1 } & 1.250,00 & 2.654,19 \\ \text { Entrevistado 2 } & 1.050,00 & 1.647,41 \\ \text { Entrevistado 3 } & 600,00 & 1.128,28 \\ \text { Entrevistado 4 } & 1.232,00 & 2.494,73 \\ \text { Entrevistado 5 } & 920,00 & 2.643,66 \\ \text { Entrevistado 6 } & 710,00 & 1.229,68 \\ \text { Entrevistado 7 } & 350,00 & 883,55 \\ \text { Entrevistado 8 } & 1.340,00 & 2.561,39 \\ \text { Entrevistado 9 } & 850,00 & 1.975,02 \\ \text { Entrevistado 10 } & 255,00 & 737,44\end{array}$

Fonte: Elaborada pelos autores (2017).

De acordo com Gazolla (2004), existem dificuldades em se calcular o valor monetário líquido do autoconsumo pelo fato da dificuldade de mensurar os custos desta produção, em que comumente se utiliza de insumos vindos do próprio estabelecimentos, o que torna-se desafiador separar as despesas que incidem sobre esta produção.

Pozzebom et al. (2015) afirma que a prática do autoconsumo sob o aspecto econômico é vantajosa, permitindo que o recurso financeiro destinado à aquisição de alimentos possa ser investido em outras necessidades. Para Fontoura (2012), possibilita a propriedade rural uma renda não monetária, que colabora para assegurar a reprodução social da família, garantindo estabilidade econômica e reduzindo a vulnerabilidade.

Esta característica já havia sido observada por Chayanov (1974) ao estudar a agricultura na Rússia. Mesmo que muitos autores não consideram a produção para autoconsumo relevante, este estudo mostrou que, caso os entrevistados fossem comprar os produtos no mercado, a renda atribuída a estes poderia comprometer a economia familiar, principalmente a pequenas propriedades rurais.

\subsection{PARA ALÉM DO VALOR MONETÁRIO: AS MÚLTIPLAS FUNÇÕES DA PRODUÇÃO PARA O AUTOCONSUMO}

Questionados sobre o uso de algum tipo de agrotóxico na produção, dos alimentos, somente um dos entrevistados confirmou ter utilizado, mas ele sinalizou sempre priorizar a utilização de produtos naturais para o combate das pragas.

Os demais entrevistados (nove) apontam que não utilizam nenhum tipo de veneno nas plantações. Por sua vez, o adubo utilizado é orgânico, dentre eles, destacando-se o esterco de galinha e de gado ou resto de alimentos, demonstrando que existe uma tendência das famílias para as práticas agroecológicas. Esta informação é confirmada pelo relatório do IPEA (2013).

Por ser destinada ao consumo próprio dos membros da família, a produção reservada ao autoconsumo, em geral, é isenta de agrotóxicos e outros produtos químicos, utilizando-se de esterco de animais, cinzas, restos de alimentos e outros materiais que não comprometem a sanidade e a qualidade - esta, não raro, e superior. Além de fortalecer a base endógena de recursos, este procedimento promove a utilização e a reciclagem de recursos disponíveis localmente, sem agredir o meio ambiente e sem 
comprometer a condição socioeconômica da família (IPEA, 2013, p. 14).

Os entrevistados, ao serem questionados sobre manter este tipo de produção, afirmam a importância do acesso a um alimento "sem veneno", "mais natural" e "de boa qualidade". Para Grisa (2007), desfrutar de alimentos "sem venenos" e saber o que está consumindo são algumas das principais justificativas para a existência do autoconsumo nos estabelecimentos.

Como se observa nesta pesquisa, a maioria dos alimentos são produzidos de forma mais natural.

Dois dos entrevistados citam que continuam produzindo para o autoconsumo por se tratar de uma tradição ensinada pelos seus pais e que gostariam que os filhos mantivessem esta prática. Citam que "é importante saber o que se está produzindo, sem agrotóxicos", "os produtos são sempre fresquinho". A tradição também é enfatizada quando falam da importância de "se manter os costumes".

Dorigon e Renk (2013, p. 40) reafirmam que:

[...] o colonial é hoje valorizado. Se noutros tempos ser da roça, da colônia, era forte estigma, agora pode adquirir valorização positiva associada a ambientação, advinda de um rural que produz artesanalmente, denotando símbolos de qualidade, de produtos sem agrotóxicos. (DORIGON E RENK, 2013, p. 40).

Em termos econômicos, os entrevistados reiteram que, ao produzir para o autoconsumo, estes "não precisam comprar no mercado, não tem custo extra", "não precisa puxar dinheiro do bolso para comprar".

Segundo o IPEA (2013).

Os agricultores que são capazes de produzir os alimentos e as matérias-primas usadas para seu consumo ou dos animais da unidade produtiva diferenciam-se das outras unidades porque não dependem integralmente de insumos externos para levar a termo o seu processo de produção, que pode tanto satisfazer as necessidades de uso próprio como servir para a troca, na forma de excedentes comercializáveis ou mesmo intercambiáveis. (IPEA, 2013, p. 13).

Dos entrevistados quatro destacam também que esta produção contribui para o bem-estar da família "como forma de passar o tempo, descarregar as energias", citam o prazer de estarem ativos, que mexer na terra é como uma forma de terapia. Citam, ainda, que: "Tenho alegria de estar na horta de mexer na terra... passa o tempo... cuidar... plantar... enquanto estou fora de casa se distrai. É bom ter as coisas, não precisar comprar, ir no mercado, e estar trabalhando é a melhor coisa. (ENTREVISTADO 10).

Estas afirmações demonstram que as tarefas relacionadas ao plantio dos alimentos são feitas de maneira prazerosa, o que intensifica o bem-estar destes indivíduos. Esta produção também auxilia no fortalecimento das relações de vizinhança, a troca de alimentos está presente, intensificando a reciprocidade.

Os agricultores sentem-se orgulhosos em produzir os alimentos que consomem e, não raro, doar para quem os visitam algum excedente ou mesmo variedades para replantio, especialmente cultivos, como temperos, chás e todo tipo de cultivo que exista no espaço da horta e do pomar. É motivo de autoestima para as 
famílias, que podem demonstrar que quase tudo de que necessitam provem do próprio trabalho na terra e ainda possuem excedentes que podem doar, como se fosse sinal de abundancia ou fartura e, portanto, de um agricultor bem-sucedido. (IPEA, 2013, p. 18).

Sintetizando, observou-se que os entrevistados atribuem múltiplas funções à produção para o autoconsumo, dentre estas, destacam-se: o acesso a um alimento mais saudável; a economia, quando não há necessidade de comprar no mercado o que se produz; a preservação dos costumes; a possibilidade de continuar ativos e a integração social, possível através da reciprocidade.

\section{CONSIDERAÇÕES FINAIS}

Com base nas informações coletadas evidencia-se uma produção de autoconsumo por parte de todos os entrevistados, o que confirma que esta prática faz parte do modo de vida das famílias rurais, mesmo aqueles que desenvolvem atividades voltadas ao mercado, organizando-se em suas atividades de maneira a trabalhar para atender as necessidades de sua propriedade e produzir para o autoconsumo.

Também se observou a diversidade de alimentos que são produzidos, sendo os mais citados alface, beterraba, salsa, repolho, batata-doce, alho, radiche, mandioca, moranga. No pomar, destaca-se a produção de laranja, bergamota, limão, jabuticaba, pêssego, uva, figo, goiaba. Ainda foram citadas outras variedades, mas em menor número. Quanto a produção de grãos, os mais mencionados foram o feijão, milho e pipoca, quesito proteínas animais, a carne bovina, frango, suína, peixes, leite, ovos; alguns dos produtos beneficiados no estabelecimento são banha, salame, chimia, vinho, queijo, conservas, compotas e o açúcar mascavo. De forma a contribuir com a manutenção de autonomia das famílias em relação ao mercado, além de proporcionar uma alimentação diversificada e mais saudável.

Há consciência dos entrevistados de que produzir para o consumo familiar é uma forma de economizar recursos financeiros e uma importante fonte de segurança alimentar, no que se refere ao acesso e qualidade dos alimentos. Também, as famílias mantêm o autoconsumo como uma atividade prazerosa, "como forma de passar o tempo, descarregar as energias".

Evidencia-se que a produção para o autoconsumo vai além de produzirem para "economizar", os entrevistados comprovam que produzem um alimento mais saudável se comparado ao alimento que se tem acesso no mercado. Para além disso, a produção para o autoconsumo permite que estes agricultores se mantenham ativos, mesmo após se aposentarem. Suas tradições também são resguardadas a partir desta prática, assim como as relações de vizinhança através da troca de produtos.

E por fim, quando responder quanto vale a produção para o autoconsumo é algo complexo, mas não resta dúvida de é mais benéfico para a saúde o consumo de produtos sem defensivos agrícolas e frescos, colhidos minutos antes de serem consumido. E os produtos quando beneficiados na propriedade são sem conservantes químicos que em termos de bem estar alimentar é primordial.

Desta forma, novos estudos são necessários principalmente para enaltecer as discussões na agricultura em relação a produção de alimentos mais saudáveis e de qualidade nutritiva, que estes não sejam apenas méritos de quem reside no campo, mas também no meio urbano, e um reflexo disso, é a grande procura por produtos orgânicos e coloniais que tem crescido cerca de $80 \%$ nos últimos anos segundo dados apresentados pelo SEBRAE (2019). 


\section{REFERÊNCIAS}

ABRAMOVAY, R. Paradigmas do capitalismo agrário em questão. 3. ed. São Paulo: Edusp, 2012.

ALVES, F. D.; LINDNER, M.; RODRIGUES, S. L. Formas de (re)produção familiar no espaço rural: Campesinato, agricultura familiar e pluriatividade. Geo. UERJ, Rio de Janeiro, ano 10, v. 2, n. 18, p. 120-140, jul./dez. 2008.

BRASIL. Ministério da Saúde. Guia alimentar para a população brasileira. 2. ed. Brasília: Ministério da Saúde, 2014.

CARNEIRO, P. A. S. A unidade de produção familiar e os enfoques teóricos clássicos. Campo-Território: Revista de Geografia Agrária, Uberlândia, v. 4, n. 8, p. 52-66, ago. 2009.

CARVALHO, D.; SOUZA, B. Novos Tempos novas engrenagens: as transformações no campo e suas dinâmicas urbanas. São Paulo: Editora do Brasil, 2012.

CECCATTO, L. Análise comparativa da viabilidade econômica e financeira das atividades avícola e leiteira. 2014. 71 f. Trabalho de Conclusão de Curso (Ciências Contábeis) - Universidade Comunitária da Região de Chapecó, Chapecó, 2014.

CHAYANOV, A. La organización de la unidad económica campesina. Buenos Aires: Nueva Visión, 1974.

CONSEA - Conferência Nacional de Segurança Alimentar e Nutricional. Princípios e Diretrizes de uma Política de Segurança Alimentar e Nutricional. Brasília: Consea, 2004. (Textos de Referência da II Conferência Nacional de Segurança Alimentar e Nutricional).

CORONEL FREITAS. Prefeitura Municipal. Distâncias. Coronel Freitas, 21 ago. 2013. Disponível em: http://www.coronelfreitas.sc.gov.br/cms/pagina/ver/codMapaltem/10318\#.

WPP3X9IrLIU. Acesso em: 20 maio 2017.

CORONEL FREITAS. Nosso Município, nossa história. Coronel Freitas: Revista do Cinquentenário, 2012.

DOMBEK, L. A. Autoconsumo e segurança alimentar em assentamentos rurais do pontal do Paranapanema. 2006. 106 f. Dissertação (Mestrado em Engenharia Agrícola) - Universidade Estadual de Campinas, Campinas, 2006.

DORIGON, C.; RENK, A. Juventude rural, produtos coloniais e pluriatividade. Chapecó: Argos, 2013.

FAJARDO, S. Complexo agroindustrial, modernização da agricultura e participação das cooperativas agropecuárias no estado do Paraná. Caminhos de Geografia, Uberlândia, v. 9, n. 27, p. 31-44, set. 2008. 
FÉLIX, S.; COELHO, I. M. Uma breve discussão em torno do conceito de Campesinato. In: SIMPÓSIO BAIANO DE GEOGRÁFICA AGRÁRIA, 1, 2010, Salvador. Anais... Salvador: UFBA, 2010.

FONTOURA, A. F. A produção para autoconsumo: características e importância para os sistemas de produção de pecuária familiar da fronteira oeste do RS. 2012. 152 f. Dissertação (Mestrado em Extensão Rural) - Universidade Federal de Santa Maria, Santa Maria, 2012.

FORNECK, E.; KLUG, J. Impactos sócio ambientais da suinocultura no oeste catarinense: do visível ao invisível. In: SIMPÓSIO NACIONAL DE HISTÓRIA - Lugar dos historiadores novos e velhos desafios, 28, 2015, Florianópolis. Anais... Florianópolis: ANPUH, 2015.

GANIMI, R. N.; ANDRADES, T. O. Revolução Verde e a apropriação capitalista. CES Revista, Juiz de Fora, v. 21, p. 43-56, 2007.

GARCIA FILHO, D. P. Guia metodológico: diagnóstico de sistemas agrários. Brasília: Incra/FAO, 1999. (Projeto de Cooperação Técnica).

GAZOLLA, M. Agricultura familiar, segurança alimentar e políticas públicas: uma análise a partir da produção para autoconsumo no território do Alto Uruguai/RS. 2004. 306 f. Dissertação (Mestrado em Desenvolvimento Rural) - Universidade Federal do Rio Grande do Sul, Porto Alegre, 2004.

GAZOLLA, M.; SCHNEIDER, S. A produção da autonomia: os "papéis" do autoconsumo na reprodução social dos agricultores familiares. Revista Estudos Sociedade e Agricultura, Rio de Janeiro, v. 15, p. 89-122, 2007.

GIL, A. C. Métodos e técnicas de pesquisa social. São Paulo: Atlas, 2008.

GOOGLE EARTH. Coronel Freitas. [s.d.]. Disponível em: https://earth.google.com/web/@-26.82595761,52.82715256,389.60309684a,18025.65439012d,35y,-0h,0t,0r. Acesso em: 24 maio 2017.

GRISA, C. A produção "pro gasto": um estudo comparativo do autoconsumo no Rio Grande do Sul. 2007. 200 f. Dissertação (Mestrado em Desenvolvimento Rural) Universidade Federal do Rio Grande do Sul, Porto Alegre, 2007.

GRISA, C.; GAZOLLA, M.; SCHNEIDER, S. A produção "invisível" na agricultura familiar: autoconsumo, segurança alimentar e políticas públicas de desenvolvimento rural. Agroalimentaria, v. 16, n. 31, p. 65-79, 2010.

GRISA, C.; SCHNEIDER, S. Fatores determinantes da produção para autoconsumo na agricultura familiar: um estudo comparativo no Rio Grande do Sul. Porto Alegre, 2008.

GRISA, C.; SCHNEIDER, S. "Plantar pro gasto": a importância do autoconsumo entre famílias de agricultores do Rio Grande do Sul. Revista de Economia e Sociologia Rural, Piracicaba, v. 46, n. 2, p. 481-515, abr./jun. 2008. 
HEISLER, Leonir., RENK, Arlene Anélia., BONAMIGO, Irme Salete. Estratégias de reprodução social no rural da microrregião de Pinhalzinho (SC). Extensão Rural, DEAER - CCR - UFSM, Santa Maria, v.25, n.2, abr./jun. 2018.

IBGE - Instituto Brasileiro de Geografia e Estatística. Santa Catarina: Coronel Freitas. Brasília: IBGE, 2016. Disponível em: http://www.cidades.ibge.gov.br/xtras/perfil.php?lang=\&codmun=420440\&search=sant a-catarina|coronel-freitas. Acesso em: 5 nov. 2016.

IPEA - Instituto de Pesquisa Econômica Aplicada. A produção para autoconsumo no Brasil: uma análise a partir do Censo Agropecuário 2006. Brasília: IPEA, 2013.

JOCHIMS, F.; DORIGON, C.; PORTES, V. M. O leite para o Oeste Catarinense. Agropecuária Catarinense, Florianópolis, v. 29, n. 3, set./dez. 2016.

KAISER, J. Santa Catarina em síntese. 2. ed. Florianópolis: Letras Brasileiras, 2014. KAUTSKY, K. A questão agrária. Porto: Portucalense, 1972.

KONRAD, J.; SILVA, C. A. Agricultura familiar no oeste catarinense: da colônia à integração. In: ENCONTRO NACIONAL DE GEOGRAFIA AGRÁRIA, 21, 2012, Uberlândia. Anais... Uberlândia, 2012.

LEITE, S. P. Autoconsumo y sustentabilidad en la agricultura familiar: una aproximación a La experiencia brasileña. In: BELIK, Walter (Ed.). Políticas de seguridade alimentaria y nutrición en America Latina. São Paulo: Hucitec, 2004.

LENIN, V. I. O desenvolvimento do Capitalismo na Rússia: o processo de formação do mercado interno para a grande indústria. 2. ed. São Paulo: Nova Cultural, 1985.

LIMA, R. Educação de antigamente e de hoje. Revista Espaço Acadêmico, Maringá, ano 9, n. 107, p. 67-71, abr. 2010.

MALUF, R. S. J.; MENEZES, F. Segurança Alimentar e Nutricional. Petrópolis: Vozes, 2007.

MARQUES, M. I. M. A atualidade do uso do conceito de camponês. Revista Nera, Presidente Prudente, n. 12, p. 57-67, 2012.

MENASCHE, R.; MARQUES, F. C.; ZANETTI, C. Autoconsumo e segurança alimentar: a agricultura familiar a partir dos saberes e práticas da alimentação. Revista de Nutrição, Campinas, v. 21, p. 145s-158s, jul./ago. 2008.

MINAYO, M. C. S. O desafio do conhecimento: pesquisa qualitativa em saúde. São Paulo: Hucitec; Abrasco, 1992.

MINETTO, M. C. Produção para autoconsumo na agricultura familiar em Santo Ângelo, RS. 2011. 81 f. Trabalho de Conclusão de Curso (Tecnólogo em Planejamento e Gestão para o Desenvolvimento Rural) - Universidade Federal do Rio Grande do Sul, Porto Alegre, 2011. 
MIOR, L. C. Agricultura familiar, agroindústria e desenvolvimento territorial. In: COLÓQUIO INTERNACIONAL DE DESENVOLVIMENTO RURAL SUSTENTÁVEL, 2, 2007, Florianópolis. Anais... Florianópolis, 2007.

PELEGRINI, G.; GAZOLLA, M. A agroindustrialização da produção como estratégia de reprodução social da agricultura familiar. Estudos Sociedade e Agricultura, Rio de Janeiro, v. 17, n. 2, p. 332-378, 2013.

PIVA, A. S. Formação do Sistema Agroindustrial e os fluxos migratórios na mesorregião oeste catarinense. 2010. 85 f. Monografia (Graduação em Ciências Econômicas) - Universidade Federal de Santa Catarina, Florianópolis, 2010.

POZZEBOM, L. et al. Repercussões territoriais das feiras de produtos coloniais e agroecológicos de Chapecó/SC: considerações sobre a SAN e o autoconsumo dos agricultores familiares. In: SEMINÁRIO INTERNACIONAL SOBRE DESENVOLVIMENTO REGIONAL, 7, 2015, Santa Cruz do Sul. Anais... Santa Cruz do Sul, 2015.

SEBRAE. A força do empreendedor brasileiro. Disponível em:http://www.sebrae.com.br/sites/PortalSebrae/canais_adicionais/conheca_quems omos. Acesso em: 27 jul de 2019.

VAN DER PLOEG, J. D. Camponeses e a arte da agricultura. São Paulo: Unesp, 2016.

VAN DER PLOEG, J. D. Rural sociology and the new agrarian question: a perspective from the Netherlands. Sociologia Ruralis, v. 32, n. 2, p. 240-246,1993.

WANDERLEY, M. N. B. O campesinato brasileiro: uma história de resistência. Revista de Economia e Sociologia Rural, Brasília, v. 52, p. 25-44, 2014.

WOORTMANN, E. F.; WOORTMANN, K. O trabalho da terra: a lógica e a simbólica da lavoura camponesa. Brasília: Editora Unb, 1997.

WOORTMANN, K. "Com Parente Não se Neguceia": o campesinato como ordem moral. In: ANUÁRIO ANTROPOLÓGICO, n. 87. Brasília: Editora Universidade de Brasília, 1990. p. 11-73. 